\title{
Association of childhood pulmonary tuberculosis with exposure to indoor air pollution: a case control study
}

\author{
Nkosana Jafta ${ }^{1 *}$ D, Prakash M. Jeena ${ }^{2}$, Lars Barregard ${ }^{3}$ and Rajen N. Naidoo ${ }^{1}$
}

\begin{abstract}
Background: Crude measures of exposure to indicate indoor air pollution have been associated with the increased risk for acquiring tuberculosis. Our study aimed to determine an association between childhood pulmonary tuberculosis (PTB) and exposure to indoor air pollution (IAP), based on crude exposure predictors and directly sampled and modelled pollutant concentrations.

Methods: In this case control study, children diagnosed with PTB were compared to children without PTB. Questionnaires about children's health; and house characteristics and activities (including household air pollution) and secondhand smoke (SHS) exposure were administered to caregivers of participants. A subset of the participants' homes was sampled for measurements of $\mathrm{PM}_{10}$ over a 24-h period $(n=105)$, and $\mathrm{NO}_{2}$ over a period of 2 to 3 weeks $(n=82)$. IAP concentrations of $\mathrm{PM}_{10}$ and $\mathrm{NO}_{2}$ were estimated in the remaining homes using predictive models. Logistic regression was used to look for association between IAP concentrations, crude measures of IAP, and PTB.

Results: Of the 234 participants, 107 were cases and 127 were controls. Pollutants concentrations $\left(\mathrm{\mu g} / \mathrm{m}^{3}\right)$ for were $\mathrm{PM}_{10}$ median: 48 (range: 6.6-241) and $\mathrm{NO}_{2}$ median: 16.7 (range: 4.5-55). Day-to-day variability within- household was large. In multivariate models adjusted for age, sex, socioeconomic status, TB contact and HIV status, the crude exposure measures of pollution viz. cooking fuel type (clean or dirty fuel) and SHS showed positive non-significant associations with PTB. Presence of dampness in the household was a significant risk factor for childhood TB acquisition with aOR of 2.4 (95\% Cl: 1.1-5.0). The crude exposure predictors of indoor air pollution are less influenced by day-to-day variability. No risk was observed between pollutant concentrations and PTB in children for $\mathrm{PM}_{10}$ and $\mathrm{NO}_{2}$.

Conclusion: Our study suggests increased risk of childhood tuberculosis disease when children are exposed to SHS, dirty cooking fuel, and dampness in their homes. Yet, HIV status, age and TB contact are the most important risk factors of childhood PTB in this population.
\end{abstract}

Keywords: Indoor air pollution, Childhood tuberculosis, Dampness, Secondhand smoke, Exposure assessment, Risk factors

\section{Background}

In 2016 tuberculosis (TB) is one of the leading causes of morbidity and mortality in the world with a rate of 140 (95\% Confidence Interval (CI), 915-1150) per 100,000 people and $22(95 \% \mathrm{CI}, 21-24)$ per 100,000 people respectively [1]. Of the 10.4 million annual $\mathrm{TB}$ cases reported globally in $2016,10-11 \%$ occur in children $[1,2]$ with developing countries having the biggest burden of

\footnotetext{
* Correspondence: jaftan@ukzn.ac.za

${ }^{1}$ Discipline of Occupational and Environmental Health, School of Nursing and Public Health, University of KwaZulu-Natal, 321 George Campbell Building, Howard College Campus, Durban 4041, South Africa

Full list of author information is available at the end of the article
}

this disease [1]. In South Africa, the overall reported incidence of $\mathrm{TB}$ has been constantly decreasing from a rate of 977 (95\% CI, 911-1030) per 100,000 in 2007 to 860 (95\% CI, 776-980) per 100,000 in 2013 [3]. In 2016, South Africa was one of top six countries with highest burden of TB disease in the world with an incidence rate of 781 (95\% CI, 543-1060) cases per 100,000 people [1]. The reported number of adults and children with coinfection of TB and HIV has stayed around 60\% [4].

Environmental risk factors associated with acquisition of tuberculosis include exposure to indoor air pollution (IAP) and secondhand smoke (SHS) with these factors

(c) The Author(s). 2019 Open Access This article is distributed under the terms of the Creative Commons Attribution 4.0 International License (http://creativecommons.org/licenses/by/4.0/), which permits unrestricted use, distribution, and reproduction in any medium, provided you give appropriate credit to the original author(s) and the source, provide a link to the Creative Commons license, and indicate if changes were made. The Creative Commons Public Domain Dedication waiver (http://creativecommons.org/publicdomain/zero/1.0/) applies to the data made available in this article, unless otherwise stated. 
having a higher impact on children compared to adults $[5,6]$. A meta-analysis by Patra et al. [6] showed an association between secondhand smoke (SHS) exposure and risk of active $\mathrm{TB}$ in children (pooled Odds Ratio $(\mathrm{OR})=$ 3.4, 95\% CI: 1.8-6.4) to be higher than in the adult population (pooled $\mathrm{OR}=1.3,(95 \% \mathrm{CI}: 1.0-1.7)$. Associations between exposure to IAP or SHS and TB have been estimated using crude measures of exposure to indoor air pollution, such as fuel type used in cooking and heating and the number of smokers in the house. None of the indoor air studies measured or estimated indoor pollutant concentrations, while some studies measuring outdoor air pollution looked at the relationship between air pollution and tuberculosis [7-9]. The objective of this study was to determine associations between indoor air pollution in the homes of children and pulmonary tuberculosis disease in Durban, South Africa.

\section{Methods}

The study was conducted in Durban, which is the third biggest city in South Africa with a population size estimation of 3.7 million in 2018. This city is located in the province of KwaZulu-Natal in the east coast of the country [10]. Compared to other provinces in the country KwaZuluNatal has been having high HIV/TB co-infection rate of $64 \%$ as well as TB case notification of 678 per $100,000(60 \% /$ $100,000)$ in 2015 [11].

This study employed a case-control design and the target population were children aged 0-14 years of age living in households situated in the Durban metropolitan area. The study period was from May 2011 to November 2014. Caregivers were interviewed about the children's health using standardized and validated child health questionnaire designed for this study. Environmental assessment of the households was performed with a walkthrough checklist and monitoring of indoor air pollutant concentrations.

PTB cases were identified through the diagnosing laboratory or in hospital wards and clinics. The central Prince Mshiyeni Memorial Hospital (PMMH) TB diagnosis laboratory, that tests specimen sent from three (3) district hospitals, namely King Edward VIII Hospital, Prince Mshiyeni Memorial Hospital and RK Khan Hospital, and 31 primary health clinics in Durban, were used to identify PTB cases. These hospitals and clinics were also visited to identify cases. Caregivers of the identified children were subsequently contacted for recruitment. Cases were children diagnosed as having PTB using the Xpert MTB/RIF assay (GeneXpert MTB/RIF; Cepheid, Sunnyvale, CA) and/or clinical diagnosis using the South African National TB Management Guidelines (Fig. 1) [12]. The NDoH protocol for clinical diagnosis of childhood PTB is based on clinical signs and symptoms of TB that include more than 2 weeks of cough, fatigue, fever and weigh loss or malnutrition [12].
The controls were children that had not been diagnosed with PTB. Two approaches were used in identification and recruitment of community controls. The first method was asking the caregiver of the recruited case to identify a neighbor whose child was of the same age group and sex as the case and forty-one controls were identified and recruited using this approach. As there was a general reluctance on the part of the "case" caregiver pointing out other potential "control" children, preschool and primary school parents $(n=98)$ from schools in the same neighbourhood as the case, were approached to allow their children to participate in the study. The caregivers of the controls were interviewed using the same instruments as used for the cases.

Screening of potential controls was performed by asking the caregivers about their child's recent diagnosis of TB by a health professional. Where no reported diagnosis of TB was identified, the caregiver was interviewed using the same child health questionnaire used in cases. The questionnaire had a section that enquires about symptoms that are used for PTB diagnosis in children (cough of more than 2 weeks duration, fatigue, weight loss and fever). All children that were included as controls, but reported more than two symptoms and/or reported a cough for more than two weeks $(n=21)$ were assessed a year later to determine if they developed TB. Twelve of these controls who could not be contacted were excluded, while the remainder presented with no evidence of $\mathrm{TB}$, and were retained for analysis. A detailed description of the selection of cases and controls is shown in Fig. 1.

The researcher interviewed the caregivers about their child's health using a standardised close-ended child health questionnaire in isiZulu or English. The questions were from different instruments used to investigate respiratory illnesses in general [13] and screen for childhood TB [12]. The questionnaire included information on the child's and mother's health and the socioeconomic status of the family unit. Child health data included symptoms related to TB such as night sweats, chronic cough, loss of weight and fatigue, and receipt of anti-tuberculosis therapy, other current and/or previous respiratory diseases, HIV status and associated treatment and the nutritional status. Other questions included any adult(s) diagnosed with TB (current and past), living in the same household as the child. Indicators of socio-economic status were based on educational levels of child's caregiver, employment status, household income and household crowding.

A previously validated household walkthrough instrument [14] was used by trained observers to collect information on household characteristics. The instrument consisted of documenting observations on the condition of the house and interviewing the caregiver about 


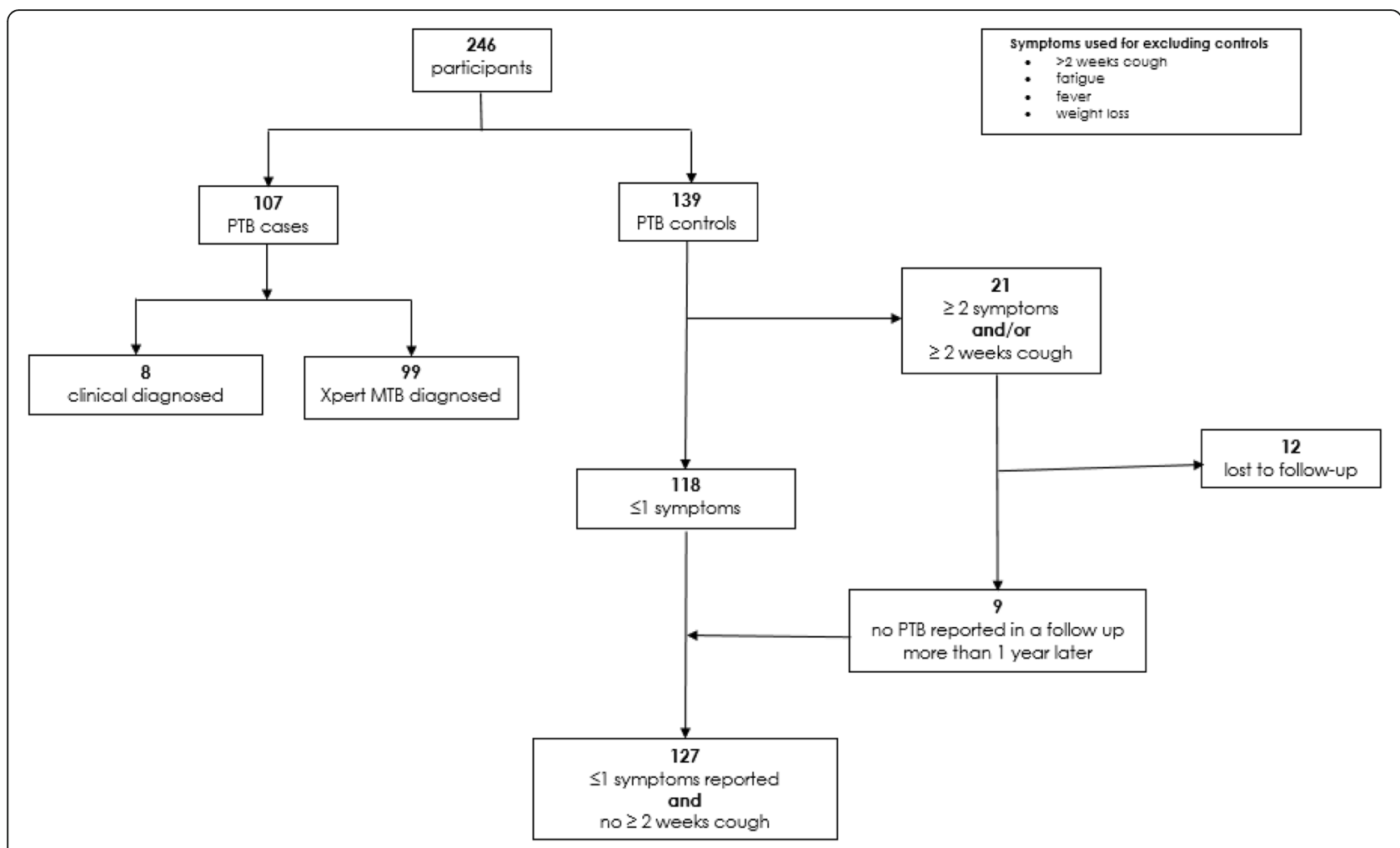

Fig. 1 Identification of participants and the definitions of pulmonary tuberculosis cases and controls used in the studies

information on household activities of the occupants. Housing conditions observations included type of house, material used in the construction of roof, walls and floor, presence of windows, presence of opening windows, visible mould growth and dampness or moisture on surfaces. Activity information collected included type of cooking and heating energy sources used, number of tobacco smokers in the home, burning of incense and use of a heater. The cooking and heating fuels used in the households were classified as clean (electricity and liquid petroleum gas (LPG)) and dirty (kerosene and wood) and those households that used a combination of clean and dirty fuels were classified as mixed fuel [14]. Children living in households with at least one smoker present were considered to be exposed to secondhand tobacco smoke (SHS) [14].

Sampling and analysis of pollutants is detailed elsewhere [14]. In brief, indoor particulate matter of diameter less than $10 \mu \mathrm{m}\left(\mathrm{PM}_{10}\right)$ was sampled over a period of $24 \mathrm{~h}$ using battery operated Airmetrics MiniVol samplers with interchangeable impactors (Tisch Environmental, Eugene, OR). Teflon filters with a support ring of $2.0 \mu \mathrm{m}$ pore size (PALL, Ann Arbor, MI) were used for sampling $\mathrm{PM}_{10}$ in the homes. $\mathrm{PM}_{10}$ concentrations were determined by gravimetric analysis in a climate-controlled laboratory. Indoor $\mathrm{NO}_{2}$ concentrations were monitored in homes using Radiello ${ }^{\circledR}$ passive samplers (Sigma-Aldrich, St Louis, MO) which were placed for a two to three-week period in the same room in which the $\mathrm{PM}_{10}$ sampling was performed. The analysis of $\mathrm{NO}_{2}$ was performed by an accredited commercial laboratory using inductively coupled plasma mass spectrometry (ICP-MS).

Particulate matter $\left(\mathrm{PM}_{10}\right)$ and $\mathrm{NO}_{2}$ concentrations were measured in 105 and 82 homes respectively. Due to limited availability of resources, these pollutant concentrations were estimated using predictive models in remaining unmeasured households $\left(\mathrm{PM}_{10}: n=129\right.$ and $\left.\mathrm{NO}_{2}: n=152\right)$. These models were developed using multivariable linear regression with measured $\mathrm{PM}_{10}$ and $\mathrm{NO}_{2}$ concentrations as dependent variables and home characteristics and occupants' activities of the measured homes as independent variables [14]. Variables that predicted $\mathrm{PM}_{10}$ concentrations were type of housing structure, total number of rooms, type of primary cooking fuel, season and number of household smokers. Nitrogen dioxide $\left(\mathrm{NO}_{2}\right)$ concentrations were predicted by distance from the roadway, type of housing structure, type of primary cooking fuel, burning of incense and season [14]. The resulting predictive models were used to predict pollutant concentrations for the homes not measured using their home characteristics and occupants' activities. Missing data points of homes that were not sampled were substituted with predicted pollutant concentrations estimated from modeling [14].

All data from completed child health questionnaires, household walkthrough checklists and analysed indoor 
air sample results were entered into Excel spreadsheets. Data was subject to logic checks to ensure validity and consistency. A validated and complete dataset was exported to STATA/IC version 13 for further analysis. Analysis was based on 107 PTB cases and 127 controls (Fig. 1).

Firstly, differences between cases and controls in frequency of child, maternal and household characteristics were tested using logistic regression. Home characteristics variables that described IAP were cooking fuel type (clean vs mix or dirty cooking fuel), secondhand smoke (no household smoker vs presence of a household smoker/s), dampness (no visible damp surface vs presence of visible damp surface), $\mathrm{PM}_{10}$ and $\mathrm{NO}_{2}$ concentrations (measured and estimated). Correlation between $\mathrm{PM}_{10}$ and $\mathrm{NO}_{2}$ concentrations was tested using Spearman correlation test.

Associations between indoor air pollution and PTB in children were then assessed using stepwise multiple variable logistic regression. Five models with each of the different indicators of indoor environment, namely cooking fuel type, SHS, dampness, $\mathrm{PM}_{10}$ and $\mathrm{NO}_{2}$ concentrations, as independent variables and childhood PTB as dependent variable were conducted. Variables that were significant determinants of childhood PTB in the univariate model or that had been shown to be risk factors in literature were selected for inclusion. A $p$-value of 0.05 and less was used as cut-off for variables to remain in the model. Age, sex and the pollutant of interest were forced into the models even if the p-value was above 0.05 . Sensitivity analyses were carried out by modeling only measured concentrations of $\mathrm{PM}_{10}$ and $\mathrm{NO}_{2}$ excluding estimated concentrations. In each model possible interaction was tested by inclusion of interaction terms such as presence of opening windows in the household, use of stove extractor fan and permitted indoor smoking.

HIV testing was performed in 143 children as part of their clinical management and was routinely undertaken as part of the research. For statistical analysis, we ran models assuming that those with unknown HIV status were negative and then models that excluded those children whose HIV status was unknown.

The study protocol was approved by the Biomedical Research Ethics Committee of University of KwaZulu-Natal (Ref. number: BREC 104/09) and permission was obtained from the health institutions involved in identification and recruitment of participants. On recruitment, the researcher explained the study to the caregivers and written or oral consent obtained from individual caregivers.

\section{Results}

Among the PTB cases, there was an equal male to female ratio, while controls had a slightly preponderance of females (58\%). The mean age of the participants was 7.3 (SD: 3.7) years and cases were somewhat younger (Table 1).
Of note, markedly fewer controls had HIV testing done (42\%) compared to the cases (84\%); $49 \%$ of PTB cases tested HIV positive compared to $4 \%$ of controls. Household TB contact was more common in cases than in controls (63\% vs $25 \%$ ). Caregivers of the cases who had completed high school were few (6\%) compared to the caregivers of the controls (15\%) (Table 1).

Visible dampness on the room surfaces $(\mathrm{OR}=1.8$, 95\% CI: 1.01-3.1), crowding (OR $=1.8,95 \%$ CI: $1.06-$ 3.2) and mixture of biomass and clean fuels for cooking $(\mathrm{OR}=2.6,95 \% \mathrm{CI}: 1.07-6.4)$ differed significantly between PTB cases and controls (Table 2). Cases were more likely to be exposed to SHS ( $48 \%$ vs $35 \%)(\mathrm{OR}=1.7,95 \% \mathrm{CI}$ : $0.98-2.8)$, with a trend towards statistical significance $(p=0.059)$.

The overall median $\mathrm{PM}_{10}$ and $\mathrm{NO}_{2}$ concentrations from the sampling program was $43 \mu \mathrm{g} / \mathrm{m}^{3}$ (range: $6.6-223$ ) and $16 \mu \mathrm{g} / \mathrm{m}^{3}$ (range: $4.5-55$ ) respectively; with both pollutants having a right-skewed distribution (Table 3). These two pollutants were weakly correlated $\left(\mathrm{r}_{\mathrm{s}}=0.30, p<0.001\right)$. Although there was a marginally higher median $\mathrm{PM}_{10}$ $\left(48 \mu \mathrm{g} / \mathrm{m}^{3}\right)$ among cases when compared to control $\left(41 \mu \mathrm{g} / \mathrm{m}^{3}\right)$, this was not statistically significant. No statistically significant differences were seen for $\mathrm{NO}_{2}$ concentrations between cases (median: $15 \mu \mathrm{g} / \mathrm{m}^{3}$ ) and controls (median: $16 \mu \mathrm{g} / \mathrm{m}^{3}$ ).

Pollutant concentrations versus child, maternal and household characteristics are shown in Table 4. Concentrations were higher in informal and crowded homes, in households with mixed and dirty cooking fuels, with SHS and in households without opening windows. $\mathrm{PM}_{10}$ concentrations were also higher in the homes of those cases in which the caregiver had lower levels of education. None of the pollutant concentrations were statistically significant between cases and controls.

In the unadjusted analysis (Table 5), dampness $(\mathrm{OR}=$ 1.8, 95\% CI: $1.01-3.1)$, cooking fuel type $(\mathrm{OR}=2.6,95 \% \mathrm{CI}$ : 1.1-6.4), and SHS (OR =1.7, 95\% CI: $0.98-2.8)$, as well as $\mathrm{PM}_{10}$ concentrations $(\mathrm{OR}=1.4,95 \% \mathrm{CI}: 0.8-2.3)$ were positively associated with PTB in children. When adjusted by other covariates, dampness, primary cooking fuel and secondhand smoke were still positively associated with an increased risk among cases, compared with controls, but with the exception of visible dampness $(\mathrm{aOR}=2.4,95 \% \mathrm{CI}$ : 1.1-5.0), these were not statistically significant (Table 5). After adjusting for other variables, the risk of PTB was lower for increase in $\mathrm{NO}_{2}$ concentration $(\mathrm{aOR}=0.4$; 95\% CI: $0.2-0.8$ ) and not significantly associated with increase in $\mathrm{PM}_{10}(\mathrm{aOR}=0.9 ; 95 \% \mathrm{CI}$ : 0.5-1.8).

There was a significant statistical association between risk factors for PTB disease: positive HIV status among children (ORs ranging from 21.5 to 31.8); younger age (ORs 0.2 to 0.3 ) and presence of a TB contact in the household (ORs 5.1 to 7.8 ) across all exposure models (Table 5). 
Table 1 Univariate analysis of child and maternal characteristics in childhood pulmonary tuberculosis cases and controls

\begin{tabular}{|c|c|c|c|}
\hline & cases $(n=107)$ & controls $(n=127)$ & \\
\hline & n (\%) & n (\%) & Crude OR (95\% Cl) \\
\hline \multicolumn{4}{|l|}{ Child Characteristics } \\
\hline \multicolumn{4}{|l|}{ Sex } \\
\hline Female & $55(51)$ & $74(58)$ & \\
\hline Male & $52(49)$ & $53(42)$ & $1.3(0.8-2.2)$ \\
\hline \multicolumn{4}{|l|}{ Age } \\
\hline$\leq 2$ & $26(24)$ & $12(9)$ & \\
\hline$>2$ to $\leq 15$ & $81(76)$ & $115(91)$ & $0.3(0.2-0.7)$ \\
\hline \multicolumn{4}{|l|}{ Hospitalization since birth } \\
\hline No & $42(39)$ & $99(78)$ & \\
\hline Yes & $65(61)$ & $28(22)$ & $5.5(3.1-9.7)$ \\
\hline \multicolumn{4}{|l|}{ HIV test done } \\
\hline No & $17(16)$ & $74(58)$ & \\
\hline Yes & $90(84)$ & $53(42)$ & $7.4(4.0-14)$ \\
\hline \multicolumn{4}{|l|}{ HIV positive ${ }^{* *}$} \\
\hline No & $46(51)$ & $49(92)$ & \\
\hline Yes & $44(49)$ & $4(8)$ & $12(3.9-35)$ \\
\hline \multicolumn{4}{|l|}{ ARV treatment before TB diagnosis ${ }^{\#}$} \\
\hline Yes & $23(52)$ & $1(25)$ & \\
\hline No & $21(48)$ & $3(75)$ & $3.3(0.3-34)$ \\
\hline \multicolumn{4}{|l|}{ Household TB contact } \\
\hline No & $39(36)$ & $95(75)$ & \\
\hline Yes & $67(63)$ & $32(25)$ & $5.0(2.8-8.7)$ \\
\hline \multicolumn{4}{|l|}{ Maternal Characteristics } \\
\hline \multicolumn{4}{|l|}{ Caregiver education } \\
\hline Post high school & $6(6)$ & $19(15)$ & \\
\hline High school + below & $101(94)$ & $108(85)$ & $3.0(1.1-7.7)$ \\
\hline
\end{tabular}

\section{Discussion}

In this, the first study to investigate associations between objective measures of indoor air pollution and childhood PTB, we did not find a significantly increased risk of acquiring childhood PTB with increasing $\mathrm{PM}_{10}$ and $\mathrm{NO}_{2}$ concentrations. Unexpectedly dampness, secondhand smoke exposure and use of dirty cooking fuels in the households were positively associated with acquiring PTB in childhood.

Some studies have described positive associations between PTB and type of fuel used for cooking for biomass [15-17]; and for kerosene [18]. However these findings were not replicated in other studies [19-21]. Although the "dirty fuels" risk among cases was increased compared to controls in our study, the majority of homes using "dirty fuel" were using kerosene. The effects of chronic exposure to kerosene smoke at a population level are not extensively studied but toxicity from exposure in animal and laboratory experiments is well-documented [22]. In the review of kerosene hazards by Lam et al. [22], the toxic effects of high levels of kerosene vapour and aerosols, and combustion products on neurological and pulmonary changes (bronchoconstriction, hyperirritability and inflammation) have been confirmed [22].

Secondhand smoke has been associated with either latent $\mathrm{TB}$ infection or active disease across different studies [5, 6, 23]. Different studies assessed exposure of children to SHS differently and therefore conclusions may differ depending on the accuracy of the methods. We report an increased risk when children are exposed to SHS measured as number of smokers living the children at home. 
Table 2 Frequency of child, maternal and household characteristics of childhood pulmonary tuberculosis cases and controls cases $(n=107)$

$\mathrm{n}(\%)$

Household Characteristics

Type of home

$\begin{array}{lll}\text { Formal } & 71(66) & 97(76) \\ \text { Informal } & 36(34) & 30(24)\end{array}$
controls $(n=127)$ n (\%)

ms in the household
$\geq 4$
60 (56)
$86(68)$
$1-3$
47 (44)
$41(32)$

$0.6(0.4-1.04)$

Presence of an opening window

$$
\begin{aligned}
& \text { All or some rooms } \\
& \text { No room }
\end{aligned}
$$

28 (26)

79 (74)

$116(91)$

Visible surface water stains/dampness

$$
\begin{aligned}
& \text { No room } \\
& \text { All or some rooms }
\end{aligned}
$$

Visible mold growth presence

$$
\begin{aligned}
& \text { No room } \\
& \text { All or some rooms }
\end{aligned}
$$

$$
\begin{aligned}
& \text { No room } \\
& \text { All or some rooms }
\end{aligned}
$$

Primary cooking fuel

$$
\begin{aligned}
& \text { Clean } \\
& \text { Mix + Dirty }
\end{aligned}
$$

$91(85)$

16 (15)

11 (9)

$0.7(0.3-1.8)$

49 (39)

$78(61)$

$1.8(1.01-3.1)$

48 (38)

$0.1(0.9-2.4)$

$76(60)$

$51(40)$

$1.04(0.6-1.8)$

119 (94)

8 (6)

$2.6(1.1-6.4)$

$57(53) \quad 82(65)$

$50(47) \quad 45(35)$

$1.6(0.9-2.7)$

Secondhand smoke

$$
\begin{aligned}
& \text { None+ Clean } \\
& \text { Mix + Dirty }
\end{aligned}
$$

\begin{tabular}{|c|c|c|c|c|}
\hline \multirow[t]{3}{*}{$\bar{n}$} & \multicolumn{2}{|c|}{$\mathrm{PM}_{10}, \mathrm{\mu g} / \mathrm{m}^{3}$} & \multicolumn{2}{|l|}{$\mathrm{NO}_{2}, \mu \mathrm{g} / \mathrm{m}^{3}$} \\
\hline & cases & controls & cases & controls \\
\hline & 107 & 127 & 107 & 127 \\
\hline $\mathrm{GM}(95 \% \mathrm{Cl})$ & $52(47-57)$ & $50(46-54)$ & $16(15-17)$ & $16(15-17)$ \\
\hline Min & 6.6 & 12 & 6.0 & 4.5 \\
\hline $25 \%$ & 37 & 41 & 12 & 12 \\
\hline Median & 48 & 41 & 15 & 16 \\
\hline $75 \%$ & 76 & 64 & 22 & 20 \\
\hline Max & 173 & 223 & 45 & 55 \\
\hline
\end{tabular}

$1.7(0.98-2.8)$

51 (48)

$64(60)$

93 (73)

$43(40)$

Significant difference in households with different characteristics for both cases and controls are shown in bold

Table $3 \mathrm{PM}_{10}$ and $\mathrm{NO}_{2}$ concentrations in the homes of children classified as PTB cases and controls in the study 
Table 4 Average concentrations of pollutants $\left(\mu \mathrm{g} / \mathrm{m}^{3}\right)$ in households of cases and controls with different characteristics

\begin{tabular}{|c|c|c|c|c|}
\hline & \multicolumn{2}{|c|}{$\begin{array}{l}\mathrm{PM}_{10} \text { concentrations } \\
\text { median (range) }\left(\mu \mathrm{g} / \mathrm{m}^{3}\right)\end{array}$} & \multicolumn{2}{|c|}{$\begin{array}{l}\text { Mean } \mathrm{NO}_{2} \text { concentrations } \\
\text { median (range) }\left(\mu \mathrm{g} / \mathrm{m}^{3}\right)\end{array}$} \\
\hline & cases $(n=107)$ & controls $(n=127)$ & cases $(n=107)$ & controls $(n=127)$ \\
\hline \multicolumn{5}{|l|}{ Child Characteristics } \\
\hline \multicolumn{5}{|l|}{ Age } \\
\hline$>2$ to $\leq 15$ & $41(21-118))$ & $41(12-119)$ & $14(7.0-45)$ & $17(9.4-26)$ \\
\hline$\leq 2$ & $49(6.6-173)$ & $47(27-223)$ & $19(6.0-34)$ & $16(4.5-55)$ \\
\hline \multicolumn{5}{|l|}{ Sex } \\
\hline Female & $48(18-173)$ & $41(13-223)$ & $15(6.0-32)$ & $16(4.5-30)$ \\
\hline Male & $49(6.6-148)$ & $41(12-119)$ & $15(8.2-45)$ & $16(9.4-55)$ \\
\hline \multicolumn{5}{|l|}{ HIV positive $e^{* *}$} \\
\hline No & $43(6.6-148)$ & $41(12-223)$ & $15(6.0-45)$ & $16(4.5-55)$ \\
\hline Yes & $53(26-173)$ & $69(31-105)$ & $15(7.5-34)$ & $16(9.4-26)$ \\
\hline \multicolumn{5}{|l|}{ Household TB contact } \\
\hline No & $48(22-173)$ & $41.0(12-136)$ & $14(6.0-34)$ & $15(4.5-52)$ \\
\hline Yes & $49(6.6-149)$ & $55(35-223)$ & $15(7.0-45)$ & $17(9.4-55)$ \\
\hline \multicolumn{5}{|l|}{ Maternal Characteristics } \\
\hline \multicolumn{5}{|l|}{ Caregiver education } \\
\hline Post high school & $37(26-48)$ & $41(31-67)$ & $12(9.4-17)$ & $15(9.4-17.4)$ \\
\hline High school + below & $51(6.6-172)$ & $41(12-223)$ & $15(6.0-45)$ & $16(4.5-55)$ \\
\hline \multicolumn{5}{|l|}{ Household Characteristics } \\
\hline \multicolumn{5}{|l|}{ Type of housing structure } \\
\hline Formal & $41(6.6-118)$ & $41(12-223)$ & $15(6.0-34)$ & $16(4.5-55)$ \\
\hline Informal & $76(26-173)$ & $76(58-136)$ & $22(7.0-45)$ & $21(11-28)$ \\
\hline \multicolumn{5}{|l|}{ Crowding } \\
\hline$\leq 2$ & $41(18-148)$ & $41(12-223)$ & $14(6.0-35)$ & $16(4.5-52)$ \\
\hline$>2$ & $65(6.6-173)$ & $76(27-119)$ & $17(7.0-45)$ & $17(9.41-55)$ \\
\hline \multicolumn{5}{|l|}{ Primary cooking fuel } \\
\hline Clean & $43(6.6-146)$ & $41(12-223)$ & $15(6.0-34)$ & $16(4.5-52)$ \\
\hline Mix + Dirty & $88(52-173)$ & $108(53-119)$ & $21.56(7.03-44.87)$ & $23(20-55)$ \\
\hline \multicolumn{5}{|l|}{ Secondary cooking fuel } \\
\hline None + Clean & $51(21-173)$ & $41(12-223)$ & $13(6.0-45)$ & $15(9.4-28)$ \\
\hline Mix + Dirty & $46(6.6-146)$ & $51(13-136)$ & $20(9.0-35)$ & $17(4.5-55)$ \\
\hline \multicolumn{5}{|l|}{ Secondhand smoke } \\
\hline No & $48(18-148)$ & $41(11-136)$ & $14(6.0-44$ & $16(4.5-55)$ \\
\hline Yes & $48(6.6-173)$ & $64(24-223)$ & $16(7.0-34)$ & $16(9.4-29)$ \\
\hline \multicolumn{5}{|l|}{ Presence of opening windows } \\
\hline Some rooms & $43(6.6-148)$ & $41(12-223)$ & $14.5(6.0-45)$ & $16(4.5-55)$ \\
\hline No room & $72(37-172)$ & $76(27-136)$ & $21(8.4-35)$ & $21(11-30)$ \\
\hline \multicolumn{5}{|l|}{ Burning of incense } \\
\hline No & $48(6.6-172)$ & $41(12-223)$ & $18.0(6.0-45)$ & $16(9.9-55)$ \\
\hline Yes & $49(21-114)$ & $51(13-136)$ & $13(7.5-29)$ & $15(4.5-44)$ \\
\hline \multicolumn{5}{|l|}{ Visible surface water stains/dampness } \\
\hline No room & $41(18-119)$ & $41(13-119)$ & $15(6.0-35)$ & $16(9.4-44)$ \\
\hline Some rooms & $51(6.6-173)$ & $48(12-223)$ & $15(7.0-45)$ & $16(4.5-55)$ \\
\hline
\end{tabular}


Table 5 Crude and adjusted odds ratios for determinants of childhood PTB in different logistic models for indoor air environment variables

\begin{tabular}{|c|c|c|c|c|c|c|c|}
\hline \multirow[b]{3}{*}{ Variable } & & \multirow{3}{*}{$\begin{array}{l}\text { Univariate } \\
\text { OR (95\% Cl) }\end{array}$} & \multicolumn{5}{|l|}{ Multivariate models } \\
\hline & & & Primary cooking fuel & Secondhand smoke & Dampness & $\mathrm{PM}_{10}$ & $\mathrm{NO}_{2}$ \\
\hline & & & aOR (95\% Cl) & $\mathrm{aOR}(95 \% \mathrm{Cl})$ & $\mathrm{aOR}(95 \% \mathrm{Cl})$ & aOR (95\% Cl) & $\mathrm{aOR}(95 \% \mathrm{Cl})$ \\
\hline \multirow[t]{2}{*}{ Primary cooking fuel } & Clean & ref & ref & & & & \\
\hline & Mix + dirty & $2.6(1.1-6.4)$ & $1.5(0.5-4.6)$ & & & & \\
\hline \multirow[t]{2}{*}{ \#Secondhand smoke } & No & ref & & ref & & & \\
\hline & Yes & $1.7(0.98-2.8)$ & & $1.2(0.6-2.3)$ & & & \\
\hline \multirow[t]{2}{*}{ Visible dampness } & No room & ref & & & ref & & \\
\hline & Some rooms & $1.8(1.01-3.1)$ & & & $2.4(1.1-5.0)$ & & \\
\hline \multirow[t]{2}{*}{$\mathrm{PM}_{10}$ concentrations } & Median + below & ref & & & & Ref & \\
\hline & Above median & $1.4(0.8-2.3)$ & & & & $0.9(0.5-1.8)$ & \\
\hline \multirow[t]{2}{*}{$\mathrm{NO}_{2}$ concentrations } & Median + below & ref & & & & & ref \\
\hline & Above median & $0.7(0.4-1.2)$ & & & & & $0.4(0.2-0.8)$ \\
\hline \multirow[t]{2}{*}{ Age } & $\leq 2$ & ref & ref & ref & ref & ref & ref \\
\hline & $>2-14$ & $0.3(0.1-0.7)$ & $0.2(0.1-0.6)$ & $0.2(0.1-0.6)$ & $0.2(0.1-0.6)$ & $0.2(0.1-0.6)$ & $0.2(0.1-0.5)$ \\
\hline \multirow[t]{2}{*}{ Sex } & Female & ref & ref & ref & ref & ref & ref \\
\hline & Male & $1.3(0.8-2.2)$ & $1.2(0.6-2.3)$ & $1.2(0.6-2.4)$ & $1.3(0.7-2.5)$ & $1.2(0.6-2.4)$ & $1.3(0.7-2.4)$ \\
\hline \multirow[t]{2}{*}{ **HIV + ve status } & No & ref & ref & ref & ref & ref & ref \\
\hline & Yes & $22(7.4-63)$ & $26(8.4-83)$ & $27(8.6-84)$ & 32 (9.7-104) & $27(8.7-87)$ & $29(9.0-93)$ \\
\hline \multirow[t]{2}{*}{ Household TB contact } & No & ref & ref & ref & ref & ref & ref \\
\hline & Yes & $5.1(2.9-9.0)$ & $6.2(3.1-12)$ & $6.3(3.2-12)$ & $6.2(3.1-12)$ & $6.5(3.3-13)$ & $7.8(3.8-16)$ \\
\hline Pseudo $R^{2}$ & & & 0.31 & 032 & 0.33 & 0.31 & 0.33 \\
\hline
\end{tabular}

All multivariate models were adjusted for age and sex. All models included crowding, HIV positive status of the child, presence of household TB contact and caregiver education

"Secondhand smoke assessed as presence of a smoker in the household

**Univariate model for HIV status results was based on those that had tested $(n=143)$. The missing observations were substituted as negative before inclusion to multivariate models

$O R$ odds ratio

$a O R$ adjusted odds ratio

Dampness on the household surfaces as a determinant of PTB in children was an interesting finding in our study. Dampness has being implicated in fungal respiratory infections $[24,25]$ but no study has found an association with PTB. In 1900, after observations of different families living in damp houses and other studies on tuberculosis, Newton [26] argued that there could be a link between exposure to dampness and tuberculosis. The explanation for this could be that dampness is associated with indoor mould growth. Mould is known to aggravate respiratory distress or colonise cavities that are a result of TB lesion in the lungs [27]. Therefore exposure to mould or dampness indicates exposure to mycotoxins, glucans and volatile organic compounds (VOCs) that compromise immunity of the respiratory system. Mycotoxin has an effect on defense mechanisms that control the mycobacterium in the lungs. Some mycotoxins reduce the functioning of ciliary function, alveolar macrophages and acquired immunity of the lungs which is a key factor in reducing the entry and/or proliferation of mycobacterium in the lungs [28].
Although there is growing literature investigating the association between PTB and exposure to air pollution $[6,8,16,29-31]$, the findings have been inconsistent. We did not find any statistically significant association between indoor $\mathrm{PM}_{10}$ or $\mathrm{NO}_{2}$ concentrations and childhood PTB. In urban environments, indoor $\mathrm{PM}_{10}$ and $\mathrm{NO}_{2}$ is the result of a multitude of sources including outdoor sources such as traffic emissions and other outdoor pollutants [32-34]. This is in contrast to rural areas where cooking fuel is the major contributor [35-37]. In this study, 10 and $40 \%$ of households that were using non-clean sources of energy for cooking had elevated $\mathrm{PM}_{10}$ and $\mathrm{NO}_{2}$ concentrations respectively [14]. However, because of the high day-to-day variability of $\mathrm{PM}_{10}$ and $\mathrm{NO}_{2}$ concentrations observed within households, a single measurement is likely to result in misclassification of exposure and drive a possible association with health effects towards the null.

Chemical constituents in the particulate matter (PM) have been demonstrated to be an important aspect when 
linking exposure to health effects [38-41]. Speciation of collected $\mathrm{PM}_{10}$ might have shown some associations with active PTB because constituents of PM such as metals and polycyclic aromatic compounds (PAHs) are known to cause respiratory distress and/or compromise lung immunity towards infections (including TB) [42-44].

Household TB contact and HIV positive status are well-known risk factors for active and latent $\mathrm{TB}$ and these findings were confirmed in our study. Both in high and low TB burden countries, household TB contact, especially sputum positive cases, have been shown to be an important risk factors for TB transmission [45-47]. Our population of interest has a high HIV burden and it was not surprising that we found that almost $50 \%$ of the PTB cases were HIV positive. Using multivariable models, we conducted sensitivity analysis by first excluding controls that were never tested for HIV, and then included them as HIV negative in the analysis, but there was no substantial change in the risk estimates. The assumption that all controls not tested for HIV were HIV negative is based on the SA DoH guidelines [48]. Only highly exposed infants (mothers who are HIV positive) are tested for HIV at birth and later. Only when the child has signs of diseases, such as TB, is the HIV test done [48]. According to the South African official statistics, the prevalence rate of HIV in children in 2016 was $2.4 \%$ as compared to $12.6 \%$ in the adult population [49].

The strength of this study is that exposure to indoor air pollution was measured, and using a well standardized household walkthrough instrument, we were able to model homes not sampled. This approach has not been adopted in previous studies examining associations with PTB. Using a study design with children as participants, minimized the confounding factors encountered when studying adults such as smoking, alcohol intake and occupational exposures. Diagnosis of PTB in children using sensitive and specific GeneXpert was also a strength of this study as this minimised the risk of misclassification of the PTB status.

Estimating exposure to indoor air pollution in epidemiological studies is always a challenge especially in the resource-constrained environment. In this study, we only measured or estimated one 24-h measurement of $\mathrm{PM}_{10}$ concentration in each home to estimate exposure of the children. Although this approach of characterizing exposure is better than no measurements at all, the variability within homes (between days) may be higher than between homes [14]. If so, a single 24-h measurement may result in misclassification of exposure to indoor air pollution. The participants' households of cases may have changed the practices when the children were diagnosed with PTB therefore the observed measured concentrations could be lower than prior the children were diseased.

\section{Conclusions}

There was a positive association between SHS and type of cooking fuel used (kerosene) and active PTB disease, although not statistically significant in adjusted estimates. We found no increased risk associated with active PTB in children and measured increased $\mathrm{PM}_{10}$ and $\mathrm{NO}_{2}$ concentrations. Although this is the first study that used actual measurements to assess indoor air pollution exposure, we noted that reliable exposure assessment is nevertheless challenging due to high variability. In addition to wellknown risk factors, such as household TB contact and HIV status, this study also suggested that indoor dampness is a risk factor for PTB in children.

\section{Abbreviations \\ DoH: Department of Health; HIV: Human immune deficiency syndrome; KZN: KwaZulu-Natal; NHLS: National Health Laboratory Services; $\mathrm{NO}_{2}$ : Nitrogen oxide; OR: Odds Ratio; PM: Particulate matter; PTB: Pulmonary tuberculosis; SHS: Secondhand smoke; $\mathrm{SO}_{2}$ : Sulphur dioxide; Stats SA: Statistics South Africa}

\section{Acknowledgements}

We wish to thank the caregivers of children who participated in the study. We also thank all the health institutions in Durban, South Africa especially King Edward VIII Hospital, Prince Mshiyeni Memorial Hospital's National Health Services Laboratory (NHLS), RK Khan Hospital and 31 primary health clinics, and the schools in Umlazi Township that gave us permission to identify and recruit participants. The abstract of this paper has been published in the African Respiratory Congress in Durban, South Africa and the International Society of Environmental Epidemiology in Sydney, Australia previously.

\section{Funding}

This study was supported by National Institutes for Health-Fogarty International (Bethesda, MD, USA) and South African TB/AIDS Research Training (SATBAT, Johannesburg, South Africa) Grant: 5U2RTW00773 and 5U2RTW007373. The funder had not role in the design, data collection, and write up of the study.

\section{Availability of data and materials}

The datasets generated and analysed during the current study are not publicly available due to more analyse to be conducted on them but are available from the corresponding author on reasonable request.

\section{Authors' contributions}

$\mathrm{NJ}$ designed the study, collected data, analysed and lead the writing of the manuscript. PJ, LB and RN contributed to the design, analysis and writing of the manuscript. All authors approved the final manuscript.

Ethics approval and consent to participate

The purpose and procedures of the study were explained to caregivers and written consent was obtained from all individual caregivers before they were recruited into the study. Verbal consent was obtained from those potential participants who could not give a written consent because of illiteracy or were not comfortable in having their signature in the consent. The protocol for this study was approved by the Biomedical Research Ethics Committee of University of KwaZulu-Natal (Ref. number: BREC 104/09) and permission was obtained from the health institutions involved.

\section{Consent for publication}

$\mathrm{N} / \mathrm{A}$

\section{Competing interests}

Rajen Naidoo is an Editorial Board Member for BMC Public health. The authors declare that they have no competing interests.

\section{Publisher's Note}

Springer Nature remains neutral with regard to jurisdictional claims in published maps and institutional affiliations. 


\section{Author details}

'Discipline of Occupational and Environmental Health, School of Nursing and Public Health, University of KwaZulu-Natal, 321 George Campbell Building, Howard College Campus, Durban 4041, South Africa. ${ }^{2}$ Discipline of Pediatrics and Child Health, School of Clinical Medicine, University of KwaZulu-Natal, Private Bag X1, Congella, Durban 4013, South Africa. ${ }^{3}$ Department of Occupational and Environmental Medicine, Sahlgrenska University Hospital and Sahlgrenska Academy at Gothenburg University, Box 414, S-405 30 Gothenburg, Sweden.

\section{Received: 25 September 2018 Accepted: 27 February 2019} Published online: 07 March 2019

\section{References}

1. World Health Organisation. 2000-2015 WHO TB burden estimates dataset. TB burden estimates. https://extranet.who.int/tme/generateCSV.asp?ds= estimates. Accessed 03 Sept 2017.

2. Jenkins HE. Global burden of childhood tuberculosis. Pneumonia. 2016;8:24. https://doi.org/10.1186/s41479-016-0018-6.

3. World Health Organisation. Global Tuberculosis Report 2014: Key indicators for the WHO region. http://www.who.int/tb/data. Accessed 03 Sept 2017.

4. World Health Organisation. Global tuberculosis report 2017. World Health Organisation. Geneva: WHO; 2017. 1-262 p. http://apps.who.int/ iris/bitstream/10665/259366/1/9789241565516-eng.pdf?ua=1. Accessed 01 Aug 2018

5. Lin $\mathrm{H}-\mathrm{H}$, Ezzati M, Murray M. Tobacco smoke, indoor air pollution and tuberculosis: a systematic review and meta-analysis. PLoS Med. 2007;4:e20.

6. Patra J, Bhatia M, Suraweera W, Morris SK, Patra C, Gupta PC, et al. Exposure to second-hand smoke and the risk of tuberculosis in children and adults: a systematic review and meta-analysis of 18 observational studies. PLoS Med. 2015;12:e1001835

7. Jassal MS, Bakman I, Jones B. Correlation of ambient pollution levels and heavily- trafficked roadway proximity on the prevalence of smear-positive tuberculosis. Public Health. 2013;127:268-74.

8. Smith G, Schoenbach VJ, Richardson DB, Gammon MD. Particulate air pollution and susceptibility to the development of pulmonary tuberculosis disease in North Carolina: an ecological study. Int J Environ Res. 2014;24:103-12.

9. Smith GS, Van Den Eeden SK, Garcia C, Shan J, Baxter R, Herring AH, et al. Air pollution and pulmonary tuberculosis: a nested case-control study among members of a northern California health plan. Environ Health Perspect. 2016;124:761-8.

10. Statistics South Africa (Stats SA). Mid-Year Population Estimates - South Africa. Pretoria; 2018. http://www.statssa.gov.za/publications/P0302/ P03022018.pdf. Accessed 01 Aug 2018.

11. KwaZulu-Natal (KZN) Provincial Aids. Annual Progress Report 2015/16: Provincial Strategic Plan 2012-2016. 2017. https://sanac.org.za/wp-content/ uploads/2019/02/PIP_KZN_Final.pdf. Accessed 01 Aug 2018.

12. National Department of Health. National tuberculosis management guidelines, 2014. Pretoria, south Africa; 2014. p. 19-28. http://www tbonline.info/media/uploads/documents/ntcp_adult_tb-guidelines-27.5. 2014.pdf. Accessed 01 Aug 2018.

13. Mentz G, Robins TG, Batterman S, Naidoo RN. Acute respiratory symptoms associated with short term fluctuations in ambient pollutants among schoolchildren in Durban, South Africa. Environ Pollut. 2018;233: 529-39.

14. Jafta N, Barregard L, Jeena PM, Naidoo RN. Indoor air quality of low and middle income urban households in Durban, South Africa. Environ Res. 2017;156:47-56.

15. Kurmi OP, Sadhra CS, Ayres JG, Sadhra SS. Tuberculosis risk from exposure to solid fuel smoke: a systematic review and meta-analysis. J Epidemiol Community Health. 2014;68:1112-8.

16. Lin $\mathrm{H}-\mathrm{H}$, Suk C-W, Lo H-L, Huang R-Y, Enarson DA, Chiang C-Y. Indoor air pollution from solid fuel and tuberculosis: a systematic review and metaanalysis. Int J Tuberc Lung Dis. 2014;18:613-21.

17. Sumpter C, Chandramohan D. Systematic review and meta-analysis of the associations between indoor air pollution and tuberculosis. Trop Med Int Heal. 2013;18:101-8.

18. Pokhrel AK, Bates MN, Verma SC, Joshi HS, Sreeramareddy CT, Smith KR. Tuberculosis and indoor biomass and kerosene use in Nepal: a case-control study. Environ Health Perspect. 2010;118:558-64.
19. Crampin AC, Glynn JR, Floyd S, Malema SS, Mwinuka VK, Ngwira BMM, et al. Tuberculosis and gender: exploring the patterns in a case control study in Malawi. Int J Tuberc Lung Dis. 2004;8:194-203.

20. Lakshmi PVM, Virdi NK, Thakur JS, Smith KR, Bates MN, Kumar R. Biomass fuel and risk of tuberculosis: a case-control study from northern India. J Epidemiol Community Health. 2012;66:457-61.

21. Behera D, Aggarwal G. Domestic cooking fuel exposure and tuberculosis in Indian women. Indian J Chest Dis Allied Sci. 2010;52:139-43.

22. Lam NL, Smith KR, Gauthier A, Bates MN. Kerosene: a review of household uses and their hazards in low- and middle-income countries. J Toxicol Environ Heal Part B Crit Rev. 2012;15:396-432.

23. Jafta N, Jeena PM, Barregard L, Naidoo RN. Childhood tuberculosis and exposure to indoor air pollution: a systematic review and meta-analysis. Int J Tuberc Lung Dis. 2015;19:596-602.

24. Kilpeläinen M, Terho EO, Helenius H, Koskenvuo M. Home dampness, current allergic diseases, and respiratory infections among young adults. Thorax. 2001;56:462-7.

25. Norbäck D, Lu C, Zhang Y, Li B, Zhao Z, Huang C, et al. Common cold among pre-school children in China - associations with ambient PM10 and dampness, mould, cats, dogs, rats and cockroaches in the home environment. Environ Int. 2017;103:13-22

26. Newton RC. Dampness as a factor in tuberculosis. Trans Am Clin Climatol Assoc. 1900;16:15-28.

27. Kuhn DM, Ghannoum MA. Indoor mold, toxigenic fungi, and Stachybotrys chartarum: infectious disease perspective fungal organisms in damp buildings. Clin Microbiol Rev. 2003;16:144-72.

28. Antonissen G, Martel A, Pasmans F, Ducatelle R, Verbrugghe $E_{\text {, }}$ Vandenbroucke $V$, et al. The impact of Fusarium mycotoxins on human and animal host susceptibility to infectious diseases. Toxins. 2014;6:430-52.

29. Altet MN, Alcaide J, Plans P, Taberner JL, Salto E, Folguera L, et al. Passive smoking and risk of pulmonary tuberculosis in children immediately following infection:a case-control study. Tuber Lung Dis. 1996;77:537-44.

30. Elf JL, Eke O, Rakgokong M, Variava E, Baliram Y, Motlhaoleng K, et al. Indoor air pollution from secondhand tobacco smoke, solid fuels, and kerosene in homes with active tuberculosis disease in South Africa. BMC Res Notes. 2017:10:591. https://doi.org/10.1186/s13104-017-2892-2.

31. Kan X, Chiang C-Y, Enarson DA, Chen W, Yang J, Chen G. Indoor solid fuel use and tuberculosis in China: a matched case-control study. BMC Public Health 2011;11:498. doi:1471-2458/11/498.

32. Lai HK, Bayer-Oglesby L, Colvile R, Gotschi T, Jantunen MJ, Kunzli N, et al. Determinants of indoor air concentrations of PM2.5, black smoke and NO2 in six European cities (EXPOLIS study). Atmos Environ. 2006;40:1299-313.

33. Shezi B, Jafta N, Sartorius B, Naidoo RN, Shezi B. Developing a predictive model for fine particulate matter concentrations in low socio-economic households in Durban, South Africa. Indoor Air. 2018;28:228-37.

34. You S, Tong YW, Neoh KG, Dai Y, Wang C-H. On the association between outdoor PM2.5 concentration and the seasonality of tuberculosis for Beijing and Hong Kong. Environ Pollut. 2016;218:1170-9.

35. Ni K, Carter E, Schauer JJ, Ezzati M, Zhang Y, Niu H, et al. Seasonal variation in outdoor, indoor, and personal air pollution exposures of women using wood stoves in the Tibetan plateau: baseline assessment for an energy intervention study. Environ Int. 2016;94:449-57.

36. Baumgartner J, Schauer JJ, Ezzati M, Lu L, Cheng C, Patz J, et al. Patterns and predictors of personal exposure to indoor air pollution from biomass combustion among women and children in rural China. Indoor Air. 2011;21:479-88.

37. Bartington SE, Bakolis I, Devakumar D, Kurmi OP, Gulliver J, Chaube G, et al. Patterns of domestic exposure to carbon monoxide and particulate matter in households using biomass fuel in Janakpur, Nepal. Environ Pollut. 2017;220:38-45.

38. Ibrahimou B, Salihu HM, Aliyu MH, Anozie C. Risk of preeclampsia from exposure to particulate matter (PM2.5) speciation chemicals during pregnancy. J Occup Environ Med. 2014;56:1228-34.

39. Kocbach Bølling A, Pagels J, Yttri KE, Barregard L, Sallsten G, Schwarze PE, et al. Health effects of residential wood smoke particles: the importance of combustion conditions and physicochemical particle properties. Part Fibre Toxicol. 2009;6:29. https://doi.org/10.1186/1743-8977-6-29.

40. Krall JR, Anderson GB, Dominici F, Bell ML, Peng RD. Short-term exposure to particulate matter constituents and mortality in a national study of U.S. urban communities. Environ Health Perspect. 2013;121:1148-53.

41. Secrest MH, Schauer JJ, Carter E, Baumgartner J. Particulate matter chemical component concentrations and sources in settings of household solid fuel use. Indoor Air. 2017;27:1052-66. 
42. Boelaert JR, Gomes MS, Gordeuk VR. Smoking, iron, and tuberculosis. Lancet. 2003;362:1243-4.

43. Karavitis J, Kovacs EJ. Macrophage phagocytosis: effects of environmental pollutants, alcohol, cigarette smoke, and other external factors. J Leukoc Biol. 2011;90:1065-78.

44. Siddiqui MS, Fakih MAH, Burney WA, Iftikhar R, Khan N. Environmental and host-related factors predisposing to tuberculosis in Karachi: a cross-sectional study. J Pioneer Med Sci. 2011;1:13-8.

45. Jubulis J, Kinikar A, Ithape M, Khandave M, Dixit S, Hotalkar S, et al. Modifiable risk factors associated with tuberculosis disease in children in Pune, India. Int J Tuberc Lung Dis. 2014;18:198-204.

46. Singh M, Mynak ML, Kumar L, Mathew JL, Jindal SK. Prevalence and risk factors for transmission of infection among children in household contact with adults having pulmonary tuberculosis. Arch Child Dis. 2005;90:624-8.

47. Triasih R, Rutherford M, Lestari T, Utarini A, Robertson CF, Graham SM. Contact investigation of children exposed to tuberculosis in South East Asia: a systematic review. J Trop Med. 2012;2012. https://doi.org/10.1155/2012/301808.

48. National Department of Health. National Consolidated Guidelines for the Prevention of Mother-to- Child Transmission of HIV (PMTCT) and the Management of HIV in Children, Adolescents and Adults. http://www. kznhealth.gov.za/family/HIV-Guidelines-Jan2015.pdf. Accessed 01 Aug 2018

49. National Department of Health, South African Medical Research Council, The DHS Program. South African Demographic and Health Survey 2016: Key Indicators. http://www.statssa.gov.za/publications/Report 03-00-09/Report 03-00-092016.pdf. Accessed 01 Aug 2018.

Ready to submit your research? Choose BMC and benefit from:

- fast, convenient online submission

- thorough peer review by experienced researchers in your field

- rapid publication on acceptance

- support for research data, including large and complex data types

- gold Open Access which fosters wider collaboration and increased citations

- maximum visibility for your research: over $100 \mathrm{M}$ website views per year

At $\mathrm{BMC}$, research is always in progress.

Learn more biomedcentral.com/submissions 